\title{
Um retorno ao clássico "A ilha do tesouro": uso de narrativa na produção de fanfiction
}

\author{
Andréia Teixeira ${ }^{\mathrm{i}}$ \\ Ana Carolina Correia Almeida ${ }^{\text {ii }}$
}

\section{RESUMO}

Este artigo investigou a prática de leitura e escrita de narrativas de ficção de alunos do Ensino Médio, por meio do gênero digital fanfiction. A pesquisa contou com a participação de 29 alunos e de uma professora de uma escola da Rede Pública Estadual de Minas Gerais. Trata-se de um estudo de caso, cuja fundamentação teórica e metodológica deu-se à luz de autores que discutem linguagem, gêneros discursivos e tecnologia digital. Os procedimentos metodológicos escolhidos para nortear o estudo foram: pesquisa de campo, bibliográfica e observação participante. $\mathrm{O}$ estudo apresentou a relevância do gênero no ensino-aprendizagem e a sua colaboração para ampliar as capacidades de leitura e escrita dos alunos da escola pública. Além disso, possibilitou a produção autoral de texto narrativo em um dos seus contextos de uso no domínio público.

Palavras-chave: Leitura e escrita; Gêneros digitais; Fanfic.

\begin{abstract}
This paper has investigated the practice of reading and writing fiction narratives by high school students within the fanfiction digital genre. Twenty-nine students and a teacher from a public school in the State of Minas Gerais participated in this research. For its theoretical framework, this case study referred to the conceptual and methodological contributions of authors who discuss language, discursive genres, and digital
\end{abstract}

\footnotetext{
i Doutoranda em Linguística e Língua Portuguesa pela Pontifícia Universidade Católica de Minas Gerais (PUC-Minas), mestre em Educação pela Faculdade de Educação da Universidade Federal de Minas Gerais (FaE/UFMG), Especialista em Língua Portuguesa, Leitura e Produção de Textos. Pós-graduada em Psicopedagogia e Docência no Ensino Superior, graduada em Pedagogia e Letras - Português/Espanhol. Professora da Rede Pública Municipal de Rio Acima - Minas Gerais (MG). Possui experiência no ensinoaprendizagem de Língua Portuguesa nas redes pública e particular, incluindo EAD no Ensino Superior. Investiga proficiência leitora, letramentos, letramento acadêmico, TICs, formação docente, avaliação educacional e escrita acadêmica. https://orcid.org/0000-0002-0642-4301 | andreia.teixeiran1@hotmail.com

ii Doutoranda e mestre em Linguística e Língua Portuguesa pela Pontifícia Universidade Católica de Minas Gerais. Especialista em Língua Inglesa e em Tradução. Possui graduação em Letras habilitação em Português, Inglês e Espanhol. É Assessora Pedagógica e responsável pelos projetos de extensão do Centro de Apoio à Educação a Distância da Universidade Federal de Minas Gerais. Tem experiência na produção de materiais didáticos para EAD. Interesses: Linguagem e Tecnologia, Educação a Distância e Ensino de Línguas. É bolsista Capes II. https://orcid.org/0000-0002-6778-8715 | anacarolinacorreiaalmeida@ gmail.com
} 
technology. The methodological procedures chosen to guide this study were: field research, bibliographic research, and participatory observation. This investigation presents the relevance of genre in teaching-learning and how it helps to expand publicschool students' reading and writing skills. Besides that, it enabled the production of authorial narratives in one of its possible contexts in the public domain.

Keywords: Reading and writing; Digital genres; Fanfic.

\section{CONSIDERAÇÕES INICIAIS: EM BUSCA DO TESOURO PERDIDO}

A sociedade atual tem pautado suas relações a partir do uso constante das Tecnologias Digitais de Informação e Comunicação (TDIC), o que traz novos sentidos e significados para as interações sociais, afetivas, econômicas e, inclusive, para o processo de construção do conhecimento, uma vez que se vive na "era da Cibercultura", conforme denomina Lévy (1999). A partir disso, os efeitos do uso da linguagem em tempos de tecnologias digitais podem ser vislumbrados, em sua totalidade, em aspectos do campo de estudos da linguagem e, consequentemente, são necessárias novas formas de ensinar a leitura e a escrita no âmbito da sala de aula.

Neste sentido, o mais novo "suporte" textual, a tela digital, possibilita aos leitores usarem, processarem e intervirem, infinita e livremente, mais do que em qualquer um dos modos mais antigos: “o livro" (CHARTIER, 1998, p. 88). Contudo, essas intervenções dão lugar a novos escritos e obviamente novos gêneros discursivos, o que Marcuschi (2005) denomina como gêneros emergentes, e tais ações ocorrem porque contamos com "novas tecnologias e ferramentas de leitura-escrita que, convocando novos letramentos, configuram os enunciados em sua multissemiose" (ROJO, 2013, p. 20), isto é, há de se convocar a natureza dos textos impressos e dos digitais.

Diante desse cenário, este trabalho apresenta práticas sociais letradas de jovens alunos no suporte digital e explora as experiências de aprendizagem desses sujeitos. Também inseridas nessas práticas, a produção e a utilização de textos online ocupam grande parte da vida desses alunos, visto que a maioria delas são digitais e mediadas por algum texto. Dialogando com esse contexto, este artigo é o resultado de uma pesquisa de abordagem qualitativa, realizada no espaço da sala de aula de Língua Portuguesa de 
uma escola da Rede Pública Estadual, localizada na Região Metropolitana de Belo Horizonte, Minas Gerais (MG). O objetivo foi investigar a prática de leitura e escrita de narrativas de ficção, por meio do gênero digital fanfiction. Para tanto, participaram deste estudo uma turma do $1^{\circ}$ ano do Ensino Médio, com 29 alunos e uma professora de Língua Portuguesa. Trata-se de um estudo de caso, pois se tem como "objeto de estudo único e específico, um sistema de ensino, uma sala de aula de uma escola, o trabalho de uma professora" (DENZIN; LINCOLN, 2005, p. 378), que articula teorias e práticas pedagógicas, valorizando a leitura e a escrita no suporte digital.

Para proporcionar esta discussão, com efeito de uma melhor organização, este estudo está dividido em cinco seções. A primeira delas discorre sobre a temática, isto é, o objeto de investigação. Já a segunda, se caracteriza por discutir o trabalho com a leitura e a escrita em narrativa de ficção e a inserção do gênero digital fanfiction no espaço da sala de aula. A terceira seção apresenta os instrumentos metodológicos utilizados para a construção do desenho da pesquisa. A quarta seção traz a análise dos dados, a partir das fanfictions produzidas pelos alunos da pesquisa. Na quinta e última seção, estão as considerações finais e, em seguida, encontram-se as referências que possibilitaram a fundamentação teórica e conceitual deste estudo.

\section{NARRATIVA DE FICÇÃO ELABORADA POR FÃ: O EMBARQUE NA LEITURA E ESCRITA DO GÊNERO FANFIC}

Nas últimas décadas, o campo epistêmico de estudo que abarca as práticas sociais de leitura e escrita tem ganhado visibilidade no cenário linguístico e educacional e, em razão desse contexto, essas práticas letradas vêm permanecendo na pauta das principais discussões do campo da linguagem. Nesse sentido, estudos como os de Rojo (2012, 2013), Assis (2014, 2015), Lopes (2016), entre outros, vêm demonstrando a preocupação acerca dos letramentos de alunos no período de escolarização, no âmbito escolar e acadêmico.

Letramento - ou letramentos no plural, pois há mais de um letramento - é uma noção oriunda do aporte teórico e conceitual de Soares (2001, p. 47), precursora desses estudos no Brasil e, portanto, é concebido como "o estado ou condição de quem, não 
apenas sabe ler e escrever, mas cultiva as práticas sociais que usam a escrita" e a leitura na diversidade das manifestações da linguagem no espaço social.

Partilhando dessa mesma ótica sobre a multiplicidade de manifestações da linguagem, Lopes (2016) defende que, atualmente, a diversidade de requisitos sociais e de participação dos sujeitos no uso da leitura e da escrita em eventos e demandas dessas práticas exige que pesquisadores busquem perspectivas multidisciplinares para cumprir a agenda de trabalhos sociais, a fim de convocar "mais de um posicionamento teóricometodológico, uma ação implicada e comprometida de fato com os processos" (LOPES, 2016, p. 90) de construção do saber do sujeito, como também de sua relação com a leitura e escrita de um texto.

Alinhada a essa visão abordada por Lopes, Rojo (2012, 2013), se posiciona frente a esse cenário de estudos linguísticos e, numa atitude responsiva, propõe ampliar a discussão sobre os letramentos, abrindo espaço para uma nova perspectiva, que ela mesma denomina de multiletramentos. Segundo a autora, a noção de multiletramentos indicia, em especial, dois modos importantes de diversidades, principalmente as urbanas: "a multiplicidade cultural das populações e a multiplicidade semiótica de constituição de textos por meio dos quais ela se informa e se comunica" (ROJO, 2012, p. 13).

A essa concepção, cabe ainda reiterar, conforme Rojo (2013), que o prefixo "multi" na palavra multiletramentos, diz respeito à diversidade "de linguagens", símbolos e "mídias", envolvendo a produção "de significados" textuais e multimodais em âmbito atual; produzindo, de "outro lado, a pluralidade e a diversidade" culturais conduzidas pelos sujeitos nessa produção de significados (ROJO, 2013, p. 14). Portanto, compreende-se que, ao conceber os multiletramentos, o sujeito está proporcionando uma abertura para a valorização da diversidade de linguagens cotidianas, lançando mão do uso de semioses, mídias e TDIC que se prestam tanto à leitura, como à escrita de novos gêneros discursivos que circulam no domínio público da linguagem e são ressignificados por este sujeito que os lê ou os escreve. Tais textos multimodais têm entrado na vida de vários jovens estudantes, despertando-os para as práticas de leitura e a produção escrita de uma multiplicidade de novos textos presentes na sua cultura, na sua vivência e, principalmente, no seu cotidiano social. Em meio a essas demandas, 
práticas sociais e novos letramentos, tem-se presenciado o surgimento de uma multiplicidade de gêneros, sendo um deles a fanfiction ou fanfic.

De acordo com Alencar e Arruda (2019, p. 89), as fanfics são produções escritas por fãs, cujas bases estão "em livros, filmes, seriados, quadrinhos, dentre outros", de suas preferências. Murakami (2016, p. 5) partilha dessa mesma visão, e acrescenta aos seus dizeres que, de modo geral, a fanfic é um texto de tipologia narrativa, baseada entre outros, "em jogos, desenhos animados" etc., que são de interesse do fã. Essas produções normalmente abrangem as cenas, personagens e enredos das obras originais, podendo o fã realizar uma interseção entre duas obras ou mais, alterando, de forma híbrida, os enredos, as cenas, os capítulos e personagens harmoniosamente, a fim de produzir um novo texto (ALENCAR; ARRUDA, 2019).

A fanfic é um texto que possui como característica o ato de narrar, sendo vista, portanto, como uma narrativa de ficção, sem o intento de obtenção de lucros, isto é, um gênero que se presta ao engajamento crítico com textos à medida que os fãs utilizam a mídia popular para criar as suas próprias narrativas (BLACK, 2009, tradução nossa). Além disso, pelo fato de as fanfics não terem a sua "estrutura textual" definida, elas podem considerar outros modos de expressão, como, por exemplo, os de composições distintas, com destaque para "a poesia e a carta". Geralmente, estão relacionadas à "cultura de massa", embora se saiba que há poucas obras baseadas em clássicos literários (MURAKAMI, 2016, p. 5).

A sua constituição se dá por meio da união de duas palavras: fan e fiction, ambas de origem inglesa. Há também outros modos reduzidos de grafar a palavra fanfiction: "fanfic" ou simplesmente "fic". Atualmente, o estudo dessa produção escrita tem sido objeto de investigação de alguns autores do campo da linguagem como, por exemplo, Ribeiro e Jesus (2019); Teixeira e Gomes (2019); Zandonadi (2019) e tem contribuído para ampliar essa discussão.

Nesse sentido, na construção de seu aporte teórico, Zandonadi (2019) buscou respaldo em trabalhos importantes como o de Jenkins (1992), para reforçar a sua tese sobre o estudo das fanfics, porque esse último autor considera que as "produções [de fanfictions] se relacionam aos enunciados estéticos mais difundidos pelos meios de comunicação" (ZANDONADI, 2019, p. 32), conforme se verifica na atualidade. 
Também nesse viés de discussão, Alencar e Arruda (2017) afirmam que as primeiras menções acerca do surgimento das fanfics ocorreram nos Estados Unidos, em torno de 1930, e isso se deu por meio de formação de grupos que possuíam preferências comuns no que dizia respeito a obras ou séries publicadas. Estes grupos foram denominados de fandom, isto é, "fan unido". Na época, havia o intuito de esses grupos possibilitarem uma ampla divulgação de obras de ficção, e foi assim que as fanfictions surgiram por meio de publicização de fanzines (revistas de fãs).

A primeira fanzine a trazer uma fanfiction foi Spocknália, referência ao Dr. Spock, personagem da série de TV Jornada nas estrelas. Essas revistas serviam de circulação para fanfics, fanarts e toda e qualquer troca de ideias dos fãs dentro daquela comunidade de fandom (ZANDONADI, 2019, p. 32).

Segundo Alencar e Arruda (2017), as fanzines eram textos que outrora permitiam aos fãs a promoção de debates e exposição de ideais acerca de suas escolhas e predileções (de livros, seriados, quadrinhos, filmes, entre outros), tornando-se o marco de fãs nos Estados Unidos, dando origem às fanfictions que são conhecidas na contemporaneidade. Segundo Teixeira e Gomes (2019, p. 7), após a escrita:

\footnotetext{
Esses textos [...] são divulgados por fãs na internet e circulam em comunidades virtuais, bem como em blogs, sites [...] no ciberespaço. Os sujeitos responsáveis pela criação desse gênero são conhecidos como fics ou fictores. Ademais, [...] esses escritores podem ser chamados de "fanfiqueiros", ou seja, modo e/ou maneira informal que se utiliza no ciberespaço (TEIXEIRA; GOMES, 2019, p. 7).
}

Nesse processo, também se pode denominar o escritor de ficwriter. Para Alencar e Arruda (2017), esse escritor amplia as próprias capacidades de escrita e de produção textual, conforme a compreensão do objeto original escolhido para a escrita da fanfic. Tal prática se dá a partir do contexto de inserção social, considerando o gosto, o que deseja ou almeja, com o intuito de criar e de usar todas as capacidades de criatividade, por meio da escrita. Sob esses escritores, Zandonadi (2019) discorre acerca dos seus perfis, e afirma que:

Os escritores são na sua maioria amadores e jovens, apesar de já existirem enunciados estéticos que começaram como fanfic e entraram no mercado editorial, como é o caso da saga Cinquenta tons de cinza, de Erika Leonard James, publicada originalmente como fanfic do livro Crepúsculo, de Stephenie Meyer (ZANDONADI, 2019, p. 32).

Considerando esse contexto, é importante ressaltar que os gêneros que emergiram com as tecnologias, em especial, a fanfiction, "permitem observar a maior integração entre os vários tipos de semioses: signos verbais, sons, imagens e formas em 
movimento" (MARCUSCHI, 2005, p. 21). Dessa forma, é fundamental reconhecer a importância da escrita de fanfic na atual conjuntura, assim como a sua contribuição no fomento das capacidades leitoras e escritoras de um sujeito e da sua participação ativa na sociedade letrada. Nesse caso, o processo envolve o compartilhamento do texto entre os envolvidos na prática de escrita, favorecendo, principalmente, a construção de conhecimentos entre o(s) escritor(es) da fanfic (RIBEIRO; JESUS, 2019) e o(s) leitor(es), assim como o desenvolvimento das suas capacidades de leitura e escrita no suporte digital.

Entretanto, é a partir dessa interação entre autor(es) e leitor(es) que surgem diversas possibilidades de se escrever a fanfic, uma vez que ocorre por meio de várias colaborações oriundas de fãs que se tornam coautores, ao passo que se posicionam criticamente frente a esse texto, fazendo seus comentários, opinando sobre possíveis mudanças na narrativa, sugerindo ou propondo novos episódios e/ou a continuidade de um capítulo ou episódio existente. Com o intuito de ampliar essa discussão, e a fim de retomar o objeto de estudo deste artigo, segue a próxima seção, com dados de pesquisa que focalizam a produção de fanfic no socioespaço da sala de aula.

\section{A FANFICTION NO DESENVOLVIMENTO DA PESQUISA: RUMO À ESCOLHA DOS INSTRUMENTOS DO ESTUDO E CAÇA AOS DADOS}

O campo das Ciências Humanas tem se revelado um solo fértil para várias investigações e, entre outras, as ciências da linguagem vêm se destacando por meio de estudos que visam, fundamentalmente, ao pleno desenvolvimento social. A esse respeito, Bakhtin considera que o objeto de estudo dessas ciências é "o ser expressivo e falante" (BAKHTIN, 2011, p. 395). E, por ser esse sujeito falante, defende que ele "é carregado de ideologias", portanto, torna-se de suma importância "ter consciência de quem é esse sujeito e de que lugar ele fala" (ZANDONADI, 2019, p. 47), ou seja, é preciso conhecer qual é o seu contexto de inserção social.

Tendo em vista esse sujeito, tornou-se necessário conhecer o seu espaço de inserção social, as suas vivências e práticas letradas, a fim de compreender as suas preferências, os seus gostos, como também as suas escolhas. Com esses propósitos, a 
pesquisa contou com a participação de 30 sujeitos, sendo 29 alunos do $1^{\circ}$ ano do Ensino Médio e uma professora de Língua Portuguesa. Serviu de cenário a sala de aula de uma escola pública da Rede Estadual de Minas Gerais. No período de investigação, implementou-se na instituição o Projeto Leitura, Escrita e Tecnologia na Escola, sob a responsabilidade da professora regente, que fazia a interlocução com a pesquisa desenvolvida. As aulas foram planejadas pela professora e estavam em conformidade com o Projeto Político Pedagógico (PPP) da escola escolhida para a pesquisa. Para a sua execução, a professora optou por aulas/módulos que foram iniciados no final de setembro, com término previsto para o mês de dezembro de 2018.

Os procedimentos metodológicos escolhidos para nortear o estudo foram: pesquisa de campo, bibliográfica e observação participante ativa na sala de aula e no laboratório de informática. Nesses ambientes de estudo, foi especialmente relevante a valorização da palavra alheia, posto que se tornou essencial ouvir e dar voz aos sujeitos participantes da pesquisa, a partir de suas produções escritas. De acordo com a abordagem bakhtiniana, a natureza da língua está centrada nas relações sociais que se dão por meio das interações discursivas nas quais um sujeito está inserido. No entanto, nesse processo, a interação social é considerada "a espinha dorsal das discussões do Círculo de Bakhtin, [pois] é por meio dela que conceitos como enunciado, [...] gêneros, sujeitos [...] são construídos" (ZANDONADI, 2019, p. 55). Nessas relações considerase que "é o outro" quem possibilita a totalidade da visão sobre nós, e de um mesmo modo, tal visão efetua a composição “do outro" (2019, p. 44). Sendo assim, Zandonadi (2019) defende que é na relação do eu com o outro que se constroem os saberes e os sentidos. Em se tratando de uma interação verbal, lança-se mão do uso de signos, a fim de que haja compreensão.

Cada signo apresenta suma relevância, posto que é considerado o fio condutor que ultrapassa o enunciado. Sobre esse aspecto, Bakhtin (2011, p. 400) afirma que “cada palavra do texto leva para além dos seus limites. Toda interpretação é o correlacionamento de dado texto com outros textos". Portanto, foi a partir da valorização desses aspectos que a investigação teve início.

A primeira etapa consistiu na escolha dos clássicos literários que foram disponibilizados para os alunos no suporte digital. Os critérios utilizados para essa escolha foram: primeiramente, seriam obras digitais disponíveis no domínio público; em 
segundo lugar, seriam consideradas a sua relevância e a preferência para os sujeitos da pesquisa. Tendo em vista esses aspectos, foram apresentadas aos alunos seis (6) opções de livros: A Ilha do Tesouro; Aprendendo a Viver; Asgard; Aventura no Reino Verde; Saga Mundo - A Taça da Babilônia e Uma casa no interior. Os participantes tiveram a oportunidade de escolhê-las de modo democrático, e isso se fez por meio de votação eletrônica, realizada a partir do formulário do Google Docs. A análise da apuração evidenciou que nove (9) votos foram para os livros A Ilha do Tesouro e Asgard, ficando empatados. Além disso, seis (6) votos se destinaram à obra Aprendendo a Viver, dois (2) foram para Aventura no Reino Verde, outros dois (2) seguiram para Saga Mundo - A Taça da Babilônia e, por fim, um (1) foi para Uma casa no interior. Como os dois primeiros livros receberam a mesma quantidade de votos, a professora permitiu a escolha de um deles para a leitura e escrita da fanfic. Todavia, convém esclarecer que, neste estudo, optou-se por explicitar a produção de fanfics a partir da leitura de A Ilha do Tesouro. Após essa etapa, os alunos receberam todas as orientações para o início da leitura, e, para o cumprimento dessa tarefa, tiveram um prazo de trinta dias para a sua execução, porque "considera-se que o ato de ler, a leitura [e a escrita são] práticas letradas essenciais à formação cidadã" (TEIXEIRA, 2019, p. 3) e precisam ser trabalhadas na escola por todo o corpo docente.

A etapa seguinte consistiu nas apresentações das leituras em um Seminário de Literatura, espaço que possibilitou a participação e interação dos estudantes, de modo que cada um teve o seu momento para exposição de sua leitura crítica, assim como o seu posicionamento acerca da obra lida. Um dia após o Seminário, realizou-se um "Lanche Literário" e, nessa oportunidade os alunos ornamentaram a sala, a partir das leituras das duas obras escolhidas na votação. Foi um momento de descontração e interação, no qual os alunos se reuniram, confraternizaram e discutiram com os colegas acerca das suas escolhas; ouviram também as sugestões, opiniões sobre as possibilidades de produção escrita da fanfic.

A última etapa do trabalho consistiu na produção textual escrita, e esta teve início no laboratório de informática da escola. Para tanto, a professora ainda na sala de aula utilizou-se de todas as tecnologias disponíveis na escola para apresentar aos alunos alguns dos sites de fanfics: Nyah! Fanfiction; Fanfic Obsession; Fanfics Brasil. Segundo a professora, esse procedimento era importante para prepará-los para a escrita 
do gênero eleito e, nesse sentido, os jovens tiveram acesso não somente a informações e orientações importantes, como também a fanfics escritas por ex-alunos da escola e por autores que já escrevem e publicam em sites específicos.

A partir desse contexto, estabeleceram-se os acordos entre os sujeitos, de modo que as duas últimas aulas da semana passaram a ser dedicadas à prática de escrita da fanfic no laboratório da escola, usando toda a tecnologia digital disponível naquele espaço de sociointeração. Alguns alunos, com o intuito de avançar na escrita do texto, usaram os seus próprios aparatos tecnológicos residenciais para o cumprimento da tarefa. Sobre essas ações, cabe esclarecer que, no laboratório da escola, não havia computadores para todos os alunos e, em razão disso, a professora permitiu que a fanfic fosse produzida em trios, duplas ou individualmente. Isso ocorreu porque alguns alunos já possuíam essa prática social de escrita.

Também é fundamental explicitar que as solicitações para a escrita em duplas ou trios foram aceitas para possibilitar a interação e, sobretudo, a escrita colaborativa entre os alunos, visto que dois ou três sujeitos comprometidos com o seu fazer escritural podem ativar um número mais elevado de capacidades de produções escrita com maior criatividade (COSCARELLI, 2016). Além do mais, percebeu-se que havia, entre eles, alunos que não possuíam contato com tecnologias digitais e, por esse motivo, não dominavam tal prática, sendo necessária a ajuda dos colegas e da professora, a fim de promover a interação e inseri-los no mundo digital. Foi a partir desse cenário que os sujeitos da pesquisa deram início à escrita das fanfics, tendo como base a obra mais votada pelos alunos. Nessa perspectiva, a seção que segue se caracteriza por explicitar dados da produção escrita de fanfics pelos alunos participantes deste estudo.

\section{DESENTERRANDO O TESOURO: IVESTIGANDO OS DADOS ENCONTRADOS}

Para compor o presente corpus, julgamos necessário fazer um recorte dos dados apurados na pesquisa. Também foi de suma relevância ancorar este estudo a uma das obras: A Ilha do Tesouro, eleita pelos alunos para a produção escrita das fanfics. Tratase de um clássico literário escocês, escrito por de Robert Louis Stevenson, conforme a síntese que segue. 


\section{Quadro 1 - Síntese do livro A Ilha do Tesouro}

Este clássico da literatura escocesa conta a história do capitão Bill, um velho e rude marinheiro beberrão, que, perseguido por piratas, recebe o "sinal negro" e acaba por ter um derrame cerebral. Bill estava hospedado em uma pequena estalagem, onde Jim e sua mãe descobrem, dentro de um célebre baú, um mapa - o mapa do tesouro do terrível pirata Flint. Juntamente com Lorde Trelawney, eles embarcam em uma expedição para a ilha indicada no mapa, e vivem muitas aventuras.

Fonte: Biblioteca do Colégio Magno (2019). Acesso em: dez. 2019.

Imersos nessas aventuras e fazendo um retorno ao clássico A Ilha do Tesouro, os participantes produziram as narrativas de ficção e, por se destacarem no projeto escolar, foram eleitas três produções para a composição do corpus desta pesquisa. O critério eleito foi a produção de textos originais, a partir da mobilização das capacidades de leitura, escrita e criatividade dos alunos. Desse modo, após as leituras da obra escolhida, três fanfics foram selecionadas: (1) Ilha do Tesouro 2; (2) Ilha do Tesouro; (3) Jacob Wills e o roubo ao banco. Para as pesquisadoras, isso foi importante pelo fato de colocar em evidência a escrita autoral dos participantes, muito embora se saiba que os textos produzidos pelos alunos possibilitam uma infinidade de leituras e análises.

Conforme o exposto, em um movimento inicial analítico, pode-se afirmar que a fanfic pertence à tipologia narrativa e, como tal, traz no enredo personagens, narrador, conflito etc., elementos característicos desse tipo de texto, assim como de sua estrutura. Ao refletir acerca da noção de tipologia textual, são ativados saberes que dizem respeito tanto à estrutura constitutiva do texto, quanto ao seu funcionamento. Melhor dizendo, é possível compreender que um texto, "pertencente a um dado gênero discursivo, pode trazer na sua configuração vários tipos textuais", tais como, por exemplo, "a narração, [...] os quais confeccionam a tessitura do texto" (SILVA, 1999, p. 100).

Percebe-se, em análise, que a estrutura narrativa em si - levando em consideração a descrição dos cenários e personagens, bem como um conflito gerador e enredo - obteve êxito nas produções escritas. Apesar de o ato de narrar ser uma prática da existência humana e do ambiente escolar, o importante aqui é a reconstrução da textualidade e a compreensão dos efeitos de sentido provocados pelos usos dos recursos linguísticos do gênero em questão, conforme se verifica no Quadro 2. 
Quadro 2 - Elementos presentes na narrativa

\begin{tabular}{|l|l|l|l|l|}
\hline Fanfic & Cenário & \multicolumn{1}{|c|}{ Personagens } & \multicolumn{1}{|c|}{ Conflito gerador } & \multicolumn{1}{c|}{ Enredo } \\
\hline 1 & $\begin{array}{l}\text { Litoral da } \\
\text { Inglaterra }\end{array}$ & $\begin{array}{l}\text { Jim Hawking, Kristen } \\
\text { Howking, Horik, } \\
\text { Ronan, Capitão Billy } \\
\text { Bones, Freya } \\
\text { Lodbrok }\end{array}$ & $\begin{array}{l}\text { Para conseguir o } \\
\text { tesouro teria que } \\
\text { sacrificar um dos } \\
\text { filhos }\end{array}$ & $\begin{array}{l}\text { Busca ao tesouro } \\
\text { deixado pelo Rei } \\
\text { Horik }\end{array}$ \\
\hline 2 & Bristol & $\begin{array}{l}\text { Capitão Flim, Dr. } \\
\text { Livesey, Karklin, } \\
\text { cozinheiro }\end{array}$ & $\begin{array}{l}\text { O cozinheiro, pai de } \\
\text { Karklin queria matar } \\
\text { Jim para ficar com o } \\
\text { tesouro }\end{array}$ & $\begin{array}{l}\text { Busca ao tesouro e o } \\
\text { protagonista } \\
\text { apaixona pela filha do } \\
\text { cozinheiro do navio }\end{array}$ \\
\hline 3 & Dubai & $\begin{array}{l}\text { Jacob Wills, Owen } \\
\text { Hunt, Henry Castello }\end{array}$ & $\begin{array}{l}\text { Traição do amigo do } \\
\text { aeroporto que tenta } \\
\text { encontrar o tesouro } \\
\text { em uma fazenda antes } \\
\text { dos protagonistas }\end{array}$ & $\begin{array}{l}\text { Busca pelo dinheiro } \\
\text { guardado e o chip } \\
\text { com informações do } \\
\text { governo, frutos de um } \\
\text { roubo a um banco }\end{array}$ \\
\hline
\end{tabular}

Fonte: Elaboração das autoras com base nos dados de pesquisa (2018).

Em análise, observa-se que o quadro explicita uma síntese das três fanfics escolhidas para este estudo. E quanto ao desenvolvimento das narrativas, verificou-se que houve uma progressão temática de modo a apresentar uma situação inicial, um conflito gerador e um desenvolvimento das ações de maneira coerente e coesa. Houve, também, no enredo o uso de descrições e diálogos, como se vê no exemplo seguinte na Fanfiction $1^{\text {iii. }}$

\section{Quadro 3 - Fanfiction Ilha do Tesouro 2 (F1)}

Rei: - Conseguiu o que você queria?
Jim: - Sim!
Rei: - O que lhe custou?
Jim: - Tudo!
Jim voltou com sua parte do tesouro para sua casa e passou o resto de sua vida lá
com seus dois filhos e sua esposa e comprou cavalos e bois. E viveu feliz, porém triste com a
perda de seu filho.

Fonte: Dados de pesquisa (2018).

Nesse caso, apesar de algumas repetições do conectivo “e”, e de uma construção que expressa uma ideia de oposição ou contradição (ver realce), percebe-se que há uma preocupação dos sujeitos autores com a produção do texto, a ponto de utilizarem

\footnotetext{
iii Para designar as fanfics optou-se pelas abreviaturas: (F1), (F2), (F3), sendo respectivamente, Ilha do Tesouro 2, Ilha do Tesouro e Jacob Wills e o roubo ao banco.
} 
diferentes recursos da língua para determinada finalidade. Ao final da narrativa, opta-se pelo uso de diálogos com o intuito de fazer o desfecho do texto. Numa narrativa, o diálogo tem algumas funções específicas e estas são muito importantes para a construção de uma história, permitindo atingir objetivos na exposição ficcional. $O$ diálogo possibilita desempenhar funções como mostrar, em vez de contar. Isso significa que a interação entre as personagens permite antever situações e abordar temas, evitando o abuso da narração expositiva. As personagens tornam-se reais quando agem e falam, ajudando a cativar o leitor.

Em cotejo ao significado do vocábulo diálogo aqui discutido, elucida-se o sentido estrito do termo que não constitui, é claro, senão uma das formas mais importantes da interação verbal. 'Mas, pode-se compreender a palavra 'diálogo' num sentido amplo, isto é, não apenas como a comunicação em voz alta, de pessoas colocadas face a face, mas sim toda uma comunicação verbal, de qualquer tipo que seja" (BAKHTIN, 2011, p. 117).

Em consonância com esses dizeres, Volóchinov (2018, p. 219) explica que o diálogo, "pode ser compreendido de modo mais amplo não apenas como a comunicação direta [...] mas como qualquer comunicação discursiva, independentemente do tipo" que se faz presente em práticas sociais da linguagem. Valorizando essas práticas de uso da linguagem, julgou-se pertinente nessa discussão, a convocação de duas categorias analíticas: interação e autoria.

Em se tratando da primeira delas, ou seja, a interação, Volóchinov (2018, p. 219) advoga que a "interação discursiva é a realidade fundamental da língua”. Logo, infere-se que o conhecimento se constrói na interação do eu com o outro. Nesse sentido, evidenciou-se que tal interação ocupou lugar de importância nas produções escritas, uma vez que esteve presente nas trocas de textos realizadas entre os participantes da pesquisa, o que proporcionou o enriquecimento da fanfic, a partir de leituras críticas e sugestões diversas dos colegas para a inserção e criação de novos personagens, alterações no início, meio e fim, além de indicações de outros cenários, novas tramas etc.

Nessa direção, o exemplo seguinte (Quadro 4) explicita uma passagem da Fanfiction 1 (F1) e traz um novo dado para um conflito gerador; uma nova trama se 
construiu e, em razão disso, surgiram alterações no meio da história, conforme se demonstra abaixo:

\section{Quadro 4 - Fanfiction Ilha do Tesouro 2 (F1)}

Freya chegou à beira do abismo e teve uma visão que falava que o povo dela tentou quebrar as regras para conquistar o tesouro e caiu uma maldição sobre eles e que para levar o tesouro para casa teria que sacrificar um dos seus filhos.

Fonte: Dados de pesquisa (2018).

Nessa cena da fanfic um personagem é sacrificado (morto). Diferentemente dela, na versão original, não se apresenta esse tipo de sacrifício no enredo, isto é, nenhum personagem saiu de cena. É realmente fruto da ativação das capacidades de criatividade dos autores do texto, que vislumbraram novos acontecimentos na releitura e na sua produção escrita. Já, na F2, segundo se vê no próximo excerto (Quadro 5), houve a inserção de uma nova personagem: a filha do cozinheiro, situação que se tornou o clímax da história devido ao fato de o protagonista apaixonar-se pela garota.

\section{Quadro 5 - Fanfiction Ilha do Tesouro (F2)}

Foram vários dias de viagem, e durante esses longos dias, também várias descobertas. Entre elas descobri que o cozinheiro misterioso tinha uma filha, uma garota linda, por quem ele morria de ciúme.... E então o cozinheiro perguntou se a filha dele, chamada Karklin, poderia seguir viagem conosco.

Fonte: Dados de pesquisa (2018).

Com o mesmo propósito inicial investigou-se à Fanfiction Jacob Wills e o roubo ao banco (F3), conforme se explicita no exemplo abaixo.

\section{Quadro 6 - Fanfiction Jacob Wills e o roubo ao banco (F3)}

Nome dado à fanfic: Jacob Wills e o roubo ao banco

Cenário: Hotel Cinco Estrelas em Dubai

Personagens: Jacob Wills (velho maluco tatuado ladrão), Owen Hunt (amigo que ajudou a roubar o banco), Henry Castello (funcionário do hotel e fiel escudeiro).

Fonte: Dados de pesquisa (2018).

A análise indiciou uma ampla alteração no título, Jacob Wills e o roubo ao banco, pois, a escolha foi totalmente diferente dos nomes atribuídos às duas outras fanfics escolhidas para a pesquisa: (F1) Ilha do Tesouro 2; (F2) Ilha do Tesouro. Ademais, na F3 o cenário ocorre em Dubai e o tesouro é uma quantia em dinheiro 
roubado de um banco (Quadro 6). Houve, também, mudanças perceptíveis na trama da história recontada, no cenário, além de criação de novos personagens, mas o objetivo foi o mesmo: a busca por um valor em dinheiro (tesouro) escondido. Diante disso, percebese que os autores interagiram com a narrativa, dialogando com ela e criando outras possibilidades no fomento do enredo, deixando a fanfic mais emocionante.

Com os respectivos excertos, tencionou-se evidenciar que as fanfics explicitaram a desenvoltura, o fomento da competência escrita, além, é claro, das marcas da criatividade dos sujeitos no ato de narrar, expressas por meio de escolhas linguísticas, recursos, entre outros, a que os alunos lançaram mão na produção dos seus textos. Nessa prática, também, se identificou a interação entre os alunos/sujeitos, assim como entre alunos/texto (a obra) e essas ações se mostraram importantes nas três fanfictions escolhidas, uma vez que foram realizadas intervenções da professora e entre os colegas, como também a troca de textos entre os sujeitos, a fim de que o colega de sala fizesse a leitura crítica e contribuísse com sugestões para o aprimoramento da fanfic.

Em se tratando do estudo do gênero, em análise percebe-se que os alunos conduziram a construção de suas narrativas, pautados nas características do gênero escolhido (fanfic) e isso pode ser visto nas produções.

A título de exemplificação, segue um excerto da F2, cuja predominância no texto é típica de narrativa, tendo havido uma mudança no foco narrativo que passou a ser na primeira pessoa do discurso.

\section{Quadro 7- Fanfiction Ilha do Tesouro (F2)}

E então ele me disse que há muito tempo atrás, trabalhou para um pirata chamado Franco, que era muito assustador, mas que deixou um baú de herança, por ele ter sido seu braço direito...

[...] Quando eles finalmente foram embora, eu, Karklin, Dr. Liversey e o senhor que morava na margem do rio conseguimos para procurar o tesouro. E então quando finalmente o achamos, foi uma surpresa.

Fonte: Dados de pesquisa (2018).

Retomando a análise, com a finalidade de conferir objetividade à noção de autoria - segunda categoria buscou-se a contribuição de Possenti (2002), uma vez que este autor defende que "alguém se torna autor quando assume (sabendo disso ou não) fundamentalmente algumas atitudes: manter distância em relação ao próprio texto, 
usar a criatividade para evitar a mesmice e dar voz a outros enunciadores" (p.112116, grifo nosso). A partir dessa perspectiva, decidiu-se, neste estudo, analisar algumas atitudes dos sujeitos-autores. Eis alguns exemplos:

\section{Quadro 8 - Fanfiction Ilha do Tesouro (F2)}

Numa vila distante do litoral na Inglaterra no século IX, Jim Hawkings já estava com quarenta anos e com 3 filhos chamados Kristen Hawking, Horik Hawking e o Ronan.

Fonte: Dados de pesquisa (2018).

Este excerto é parte constitutiva do início da F2. Nela, o garoto da obra original (Jim Hawkins) se tornou pai de família e optou por atribuir os sobrenomes Hawkings aos filhos, exceto para o Ronan. Nessa passagem, percebe-se que há a tentativa de produzir certo distanciamento dos sujeitos-autores, iniciando a narrativa em terceira pessoa do discurso/singular, fazendo o uso da descrição do cenário. Entretanto, esse distanciamento não ocorre ao nomear o terceiro filho de "o Ronan", com o referente determinado pelo artigo definido, que passa a fazer parte de um conjunto argumentativo, demonstrando certa intimidade com o personagem, que mantém também a criatividade da história, o que se apresenta em seguida. Ademais, nesta F2, é possível observar que os sujeitos-autores usam a criatividade para "sair da mesmice", conforme mostrado no próximo exemplo.

\section{Quadro 9 - Fanfiction Ilha do Tesouro (F2)}

Logo após a visão ela contou para seu marido, que mandou ela escolher um dos seus três filhos para empurrar ele do abismo, ela com pesar no coração escolheu o Ronan que era um jovem valente que aceitou o fardo e se jogou de lá.

Fonte: Dados de pesquisa (2018).

Nesse excerto, constata-se que Ronan foi o personagem escolhido para ser sacrificado pela família para obtenção do tesouro no final da trama. Portanto, ele se jogou do penhasco para que seus familiares recebessem o tesouro e, assim, possibilitar o desfecho da trama presente na Fanfiction 2.

Em análise das fanfics, não se tencionou aferir os problemas técnicos dos textos produzidos na sala de aula, pois são na realidade produtos de um modelo de escrita subjacente às próprias práticas de ensino-aprendizagem da língua. Logo, os textos 
produzidos em situações reais atendem a demandas também reais, e delas depende o seu funcionamento. Foi por meio da valorização desse princípio que se chegou às narrativas produzidas pelos alunos.

No caso do excerto analisado, os autores empregaram uma variedade de verbos (contar, mandar, empurrar, escolher, aceitar) para introduzir em seu texto vozes/falas de outros enunciadores, e isso se tornou interessante no estudo. Com relação a esses usos verbais, é de se considerar o que já foi dito, que "pelo menos metade do" que se diz “diariamente são palavras de outrem” (BAKHTIN, 1975 apud POSSENTI, 2002, 116) empregadas em novos contextos de uso da língua, que estão constantemente em evolução. Ademais, também, é preciso concordar com Possenti (2002, p. 117) que:

\begin{abstract}
A variação é de bom tom. Mas, não se trata de variar por variar, de organizar uma lista de verbos dicendi e prometer não empregar o mesmo verbo mais de uma vez em cada texto. Essa variação só é interessante quando se obedece a tomadas de posição ou se faz sentido de outra forma. (POSSENTI, 2002, p. 117)
\end{abstract}

Nessa direção, e em plena coerência com Possenti, verifica-se no excerto analisado, que o uso de cada verbo se adequa ao contexto de produção escrita e colabora para torná-lo mais denso para a leitura dos sujeitos. Também, mais um exemplo importante se encontra na F3, pois, é outra trama, na qual se evidencia a última questão da autoria referida por Possenti (2002): dar voz aos enunciadores. Estes índices podem ser destacados conforme os exemplos a seguir:

\title{
Quadro 10 - Fanfiction Jacob Wills e o roubo ao banco (F3)
}

Logo depois todos saíram andando pelas ruínas da cidade; era uma cidade bonita, porém bem sem vida.

[...]Dois dias depois começaram a expedição à procura do tal tesouro e não demoraram muito pra achar o lugar indicado pelo mapa que dava a um abismo muito alto.

Fonte: Dados de pesquisa (2018).

Em um movimento analítico, cabe inicialmente conceber que "um dos recursos disponíveis para mencionar outros discursos é fazê-lo através de um léxico [e também o recurso sintático: sintagma adjetival] que implique uma avaliação do autor" (POSSENTI, 2002, p. 114). E, nesse sentido, no exemplo ora apresentado, as palavras bem e tal demonstram expressões que revelam essa avaliação dos sujeitos-autores em relação aos fatos, o que conduz ao desfecho dessa estória. Diante disso, percebe-se que 
"a avaliação do outro discurso, do discurso citado, pode ser mais explícita ou ser efetuada com aparência de neutralidade" (ibid.), conforme se demonstra no exemplo supracitado.

Entretanto, de acordo com a tese defendida por Possenti (2002, p.121), pode-se concluir que "há indícios de autoria quando diversos recursos da língua são agenciados mais ou menos pessoalmente - o que poderia dar a entender que se trata de um saber pessoal", singular, construído pelo sujeito. Nesse caso, advoga-se que a construção desse conhecimento é resultado de práticas sociais e discursivas nas quais o sujeito está inserido na sociedade.

\section{TESOURO CONQUISTADO: CONSIDERAÇÕES FINAIS}

Com este estudo, pretendeu-se investigar a prática de leitura e escrita de narrativas de ficção de alunos do Ensino Médio, por meio do gênero digital fanfiction. Para tanto, iniciou-se uma discussão pautada em teorias e práticas de letramentos, com bases teóricas que contemplam o ensino-aprendizagem de leitura e escrita na contemporaneidade. Nesse sentido, pôde-se conhecer uma experiência docente com o trabalho pedagógico desenvolvido no âmbito da sala de aula e no laboratório de informática da escola, espaços que serviram como cenário para a pesquisa.

Também, com o corpus escolhido, foi possível trazer para a discussão a prática escrita dos estudantes, a fim de compreendê-la, atribuindo sentido e significado aos seus novos e multiletramentos. Em análise, pode-se dizer que o estudo evidencia como adolescentes exibem ampla criatividade nas produções de narrativas e, para tanto, recorrem com frequência a uma variedade de gêneros e aparatos digitais e não digitais que possibilitam a leitura e a escrita. E, em meio a um desses gêneros cotidianos, a fanfiction entra nessas práticas letradas, e se torna uma poderosa aliada no fomento da leitura e da escrita na atual conjuntura.

Os achados evidenciaram a emergência de se trabalhar com práticas sociais, valorizando os letramentos extraescolares dos alunos, como, por exemplo, o conhecimento e uso do gênero fanfic. Além disso, o estudo apontou a relevância desse texto no ensino-aprendizagem de leitura e escrita, como também nos eventos de letramentos, colaborando para ampliar as capacidades leitoras e escritoras dos alunos do 
Ensino Médio, conforme já se verifica em trabalhos contemporâneos (TORRES, 2016; ZANDONADI, 2019) da linguagem. Ademais, possibilitou conhecer a produção autoral de texto narrativo, assim como a apropriação da linguagem em um dos seus contextos de uso no domínio público.

Por meio dessas práticas de multiletramentos, constatou-se que para que os alunos possam produzir textos caracterizados pela criatividade e pela autoria, torna-se necessário que eles tenham o direito e a possibilidade de ocupar diferentes lugares de interpretação, movimentar-se por eles e constituírem-se como participantes ativos e críticos na sociedade. Os resultados demonstraram, inclusive, que a mídia participativa contemporânea, como a escrita de fanfiction, pode servir como um dos recursos pedagógicos de utilidades para a promoção da aprendizagem na sala de aula de Língua Portuguesa.

Diante de todo o exposto, a análise ora apresentada corrobora no sentido de incentivar a leitura de textos e/ou obras consideradas clássicas, de interesse dos alunos e, para obtenção do seu interesse, torna-se necessário inová-las, a partir do trabalho com novos gêneros, fazendo uma releitura e uma retextualização, uma vez que o diálogo estabelecido entre o gênero produzido em ambiente digital e o livro impresso/na tela (A ilha do tesouro), também contribui para o fomento de capacidades leitoras, escritoras, assim como para a ampliação dos multiletramentos dos alunos na período de escolarização.

Por fim, advoga-se pela emergência de a escola e os professores se unirem em um projeto interdisciplinar, com o intuito de proporcionarem aos alunos trabalhos com práticas letradas e discursivas que valorizem, fundamentalmente, as atividades de preferências dos alunos, estimulando-lhes a construção do conhecimento a partir de proposições de leitura e escrita que tenham sentido e significado para esses sujeitos. E, para alcançarem melhores desempenhos nessas práticas letradas, também, é essencial que se propicie aos alunos oportunidades de ler e escrever sobre o objeto de sua escolha, de modo que eles possam, sim, ler e escrever, não exatamente pelo simples fato de cumprimento do currículo escolar, a fim de aferir essas capacidades letradas. Mas sim, pelo prazer e pela oportunidade de os alunos ampliarem os saberes e as capacidades de letramentos, possibilitando-lhes tanto ler como escrever os seus textos prediletos, eleitos conforme o gosto, ou mesmo pela magia e pela aprendizagem que essas práticas podem 
proporcionar-lhes ao ler e escrever um determinado texto. (TEIXEIRA; GOMES, 2020).

Desse modo, o aluno será o protagonista da construção dos seus saberes, estará participando da plena cidadania e da sociedade dos novos e multiletramentos.

\section{Referências}

ALENCAR, Daniele Alves; ARRUDA, Maria Izabel Moreira. Fanfiction: uma escrita criativa na web. Perspectivas em Ciência da Informação, v.22, n.2, p.88-103, abr.jun. 2017.

ASSIS, Juliana Alves. Ações do professor e do universitário nas práticas de ensino e de aprendizagem da escrita acadêmica: o papel da avaliação e da reescrita no processo de apropriação do gênero resenha. Eutomia, Recife, 2014, p. 543-561.

ASSIS, Juliana Alves. "Eu sei mas não consigo colocar no papel aquilo que eu sei: representações sobre os textos acadêmico-científico". In RINCK, Fanny; BOCH, Françoise; ASSIS, Juliana (Org.). Letramento e formação universitária: formar para a escrita e pela escrita. Campinas, São Paulo: Mercado das Letras, 2015, p. 402-423.

BAKHTIN, Mikhail. Estética da criação verbal. Tradução: Paulo Bezerra 6 ${ }^{\text {a }}$. ed. São Paulo. Editora WMF Martins Fontes, 2011.

BLACK, Rebecca W. Online Fan Fiction and Critical Media Literacy.Journal of Computing in Teacher Education. Volume 26/ Number 2 Winter, 2009 -10.

CHARTIER, Roger. A aventura do livro: Do leitor ao navegador. SP: EDUNESP, 1998.

COSCARELLI, Carla Viana. Navegar e ler na rota do aprender. In: COSCARELLI, Carla Viana (Org.). Tecnologias para aprender. 1. ed. São Paulo: Parábola Editorial, 192 p., 2016, p. 61-80.

DENZIN, Norman K; LINCOLN, Yvonna S. The discipline and practice of qualitative research, p.1-36. In: DENZIN, Norman K; LINCOLN, Yvonna S. Handbook of Qualitative Research, Thousand Oaks: Sage, 2005.

JENKINS, Henry. Textual poachers television fans and participatory culture. New York: Routledge, 1992.

LÉVY, Pierre. Cibercultura. (Trad. Carlos Irineu da Costa). São Paulo: Editora 34, 2009.

LOPES. Maria Angela Paulino Teixeira. Linguagem e processos de letramento: uma experiência formativa. In: KLEIMAN, A; ASSIS, Juliana (Org.). Significados e 
ressignificações do letramento: desdobramentos de uma perspectiva sociocultural sobre a escrita. Campinas, São Paulo: Mercado das Letras, 2016, p. 89-110.

MURAKAMI, Raquel Yukie. O ficwriter e o campo da fanfiction: reflexão por uma forma de escrita contemporânea. (Dissertação de Mestrado). Faculdade de Filosofia, Letras e Ciências Humanas da Universidade de São Paulo (USP), 2016.

MARCUSCHI, Luiz Antônio. Gêneros textuais: definição e funcionalidade. In: DIONÍSIO, A. P.; MACHADO, A. R.; BEZERRA, M. A. (Org.). Gêneros textuais e ensino. 4. ed. Rio de Janeiro: Lucerna, 2005.

POSSENTI, Sírio. Indícios de autoria. Revista Perspectiva, Florianópolis, v. 20, n. 01, p.105-124, jan./jun. 2002.

RIBEIRO, Ana Elisa; JESUS, Lucas Mariano de. Produção de fanfictions e escrita colaborativa: Uma proposta de adaptação para a sala de aula. Scripta, 23(48), p. 93-108, 2019.

ROJO, Roxane, Pedagogia dos multiletramentos: diversidade cultural e de linguagens na escola. In: ROJO, Roxane; MOURA, Eduardo (org.). Multiletramentos na escola. São Paulo: Parábola, Editorial, 2012, p. 11-31.

ROJO, Roxane. Gêneros discursivos do Círculo de Bakhtin e multiletramentos. In: Roxane Rojo (org.). Escol@ conectada os multiletramentos e as TICs. São Paulo: Editora Parábola, 2013, p.13-36.

SILVA, Jane Quintiliano C. Gênero discursivo e tipo textual. Scripta, . Belo Horizonte, v. 2. n. 4. p. 87-106,1999.

SOARES, Magda. Letramento: um tema em três gêneros. $2^{\mathrm{a}}$ ed. Belo Horizonte: Autêntica, 2001.

TEIXEIRA, Andréia; GOMES, Suzana dos Santos. Letramentos e formação cidadã: da decodificação à concepção de leitura como sociointeração na produção de sentido. In: Ana Cristina Fricke Matte e Francine Souza Andrade (Org.). Universidade EAD Software Livre: o fenômeno UEADSL. Coleção Texto Livre: Pensemeando o mundo. Tomo VI. São Carlos: Pedro \& João Editores, 2020, p. 199-222.

TEIXEIRA, Andréia; GOMES, Suzana dos Santos. Letramento digital no ensino médio: um estudo do gênero fanfiction nas aulas de língua portuguesa. Revista Debates em Educação, vl. 11, №. 24, maio/ago., 232-248 p, 2019.

TEIXEIRA, Andréia. Níveis de leitura de alunos da rede pública: um estudo sobre a capacidade de letramento. Mandinga - Revista de Estudos Linguísticos, [S.1.], v. 3, n. 2, p. 75-88, dec. 2019. ISSN 2526-3455. Disponível em: <http://www.revistas.unilab.edu.br/index.php/mandinga/article/view/322>. Acesso em: 14 maio, 2020. 
TORRES, Kátia Cristina de Oliveira. Experiências narrativas: Fanfics a partir de um conto de suspense. 2016. 135 p. Dissertação (Mestrado) Programa de Mestrado Profissional em Letras da Universidade Federal de Minas Gerais, 2016.

VOLÓCHINOV, Valentin. Marxismo e filosofia da linguagem: problemas fundamentais do método sociológico na ciência da linguagem, $16^{\mathrm{a}}$ ed. Tradução de Sheila Grillo e Ekaterina Vólkova - São Paulo: Editora 34, 2018 (2a edição). p. 201225.

ZANDONADI, Raquel Santos. Leituras e escrita em língua portuguesa: a fanfiction na sala de aula. 2019. 401 f. Dissertação (Mestrado Profissional em Letras) - Universidade Estadual Paulista (UNESP), Faculdade de Ciências e Letras.

Recebido em: 10/08/2020 Aceito em: 22/09/2020 